\title{
Effect of osteopathic maneuvers in the treatment of asthma: review of literature
}

\section{Efeito das manobras osteopáticas no tratamento da asma: revisão de literatura}

\author{
Rodrigo Medina Vasconcelos Lago ${ }^{1,2}$, Marco Antônio Figueiredo da Silva Filho², Alan Carlos Nery dos Santos ${ }^{3}$
}

\begin{abstract}
Introduction: Despite the high prevalence of asthma, there is no consensus in the literature regarding non-drug methods for the treatment of their symptoms. Thus, holistic therapies such as osteopathy can be viable alternatives since evidence has shown benefits of osteopathic manipulative treatment of clinical conditions such as asthma. Objective: To gather evidence tested osteopathic approach to treating the symptoms, respiratory dysfunction, medication use and quality of life of patients with asthma. Method: Electronic searches were conducted between October and November 2014. It was used as descriptors crossed, or alone in the fields "words", "subject descriptors", "title words", "title" and "abstract" the following keywords combined with Boolean operators AND and OR: Osteopathic Medicine, osteopathic manipulation, osteopathy, Spinal Manipulation, Manual Therapy, Therapy Skull Sacral, Chiropractic, Chiropractic Manipulation, Asthma. Initially they were collected all the articles that addressed the manual features used by osteopathic or chiropractic correlated with the asthma treatment published between 1998 and 2014. Results: It was found 35 articles, of which 28 were excluded because they did not conform to pre-defined criteria. Thus, seven works were part of this review. Four of them are clinical trials, two case studies and a pilot study. Conclusion: Our findings suggest that osteopathic manipulative techniques can be used as non-medicated additional resource in the treatment of patients with asthma. The reviewed studies have identified improving the quality of life, subjective perception of symptoms and reduce the use of drugs.
\end{abstract}

Keywords: Osteopathic medicine; Manipulation; Osteopathic; Asthma; Physical therapy specialty; Musculoskeletal manipulations.

\section{RESUMO}

Introdução: Apesar da elevada prevalência da asma, ainda não existe consenso na literatura quanto aos métodos não medicamentosos para o tratamento dos seus sintomas. Assim, terapias holísticas como a osteopatia, podem ser alternativas viáveis, uma vez que, evidências apontam benefícios do tratamento osteopático manipulativo em condições clínicas como a asma. Objetivo: Reunir evidências que testaram a abordagem osteopática no tratamento dos sintomas, disfunções ventilatórias, uso de medicamentos e qualidade de vida de pacientes com asma. Método: As buscas eletrônicas foram realizadas entre outubro e novembro de 2014. Utilizou-se como descritores cruzados, ou, isoladamente nos campos "palavras", "descritores de assuntos", "palavras do título", "título" e "resumo", as seguintes palavras-chave, combinadas com os operadores booleanos AND e OR: Medicina Osteopática, Manipulação Osteopática, Osteopatia, Manipulação Vertebral, Terapia Manual, Terapia Crânio Sacral, Quiropraxia, Manipulação Quiroprática, Asma e os seus correspondentes em Inglês. Inicialmente foram coletados todos os artigos que abordassem os recursos manuais utilizados pela osteopatia ou quiropraxia correlacionados com o tratamento da asma publicados entre os anos de 1998 e 2014. Resultados: Encontrados 35 artigos, dos quais 28 foram excluídos por não se adequarem aos critérios previamente definidos. Sendo assim, 7 trabalhos fizeram parte desta revisão. Dos quais, quatro são ensaios clínico, dois estudos de caso e um estudo piloto. Conclusão: Nossos achados sugerem que as técnicas manipulativas osteopáticas podem ser utilizadas como recurso não medicamentoso complementar no tratamento de pacientes com asma. Os estudos revisados identificaram melhora da qualidade de vida, percepção subjetiva dos sintomas e redução do uso de medicamentos. Palavras - chave: Medicina osteopática; Manipulação osteopática; Asma; Fisioterapia; Manipulações musculoesqueléticas.

Corresponding author: Alan Carlos Nery dos Santos. Av. Dom João Vl, 275, Brotas, Zip Code: 44657-086, Salvador (BA), Brazil. E-mail: allannery.santos@hotmail.com ${ }^{3}$ Post graduated Strictu Sensu program in Medicina e Saúde Humana, Escola Bahiana de Medicina e Saúde Pública (EBMSP), Salvador, (BA), Brazil. Full list of author information is available at the end of the article.

Financial support: None.

Submission date 3 September 2015; Acceptance date 1 December 2015; Online publication date 11 December 2015 


\section{INTRODUCTION}

Asthma is a chronic inflammatory disease of the airways associated with bronchial hyper responsiveness and obstruction of the respiratory flow. It is estimated that $\mathbf{3 0 0}$ million people worldwide have asthma and this prevalence is likely to increase due to Western lifestyle. ${ }^{(1,2)}$ In Brazil, there are around 16 million asthmatics of all ages, and as consequences this high number, it is evaluated that around 350,000 admissions by the Unified Health System network and approximately 2,000 deaths and thousands of outpatient and emergency assistance are due to this disease. ${ }^{(3)}$

Despite the high prevalence of asthma, there is no consensus in the literature regarding non-drug methods for the treatment of their symptoms. Thus, holistic therapies such as osteopathy can be viable alternatives. In fact, evidence has indicated that the osteopathic manipulative treatment (OMT) can be applied in a variety of clinical conditions, including respiratory system such as asthma. ${ }^{(4,5)}$

The OMT can be defined as: therapeutic application of forces by a manually guided osteopath to improve the physiological function and/or homeostatic support that has been altered by somatic dysfunction. According to the glossary of osteopathic terminology, the manipulative techniques ranging from articulation techniques, visceral manipulation including cranial osteopathy. ${ }^{(6,7)}$

The manipulative technique acts directly on the sympathetic and parasympathetic system, acting on the nervous system can lessen the symptoms by improving the quality of life of patients. The parasympathetic innervation of the lung and diaphragm structures is supplied by the vagus nerve. Since the origin of the sympathetic innervation of the lungs and bronchi originated between the fourth and fifth thoracic vertebrae, and the paraspinal ganglia is immediately behind the costovertebral junction of the upper thoracic region. ${ }^{(8)}$

There are some aspects where the OMT expects to benefit patients with asthma. First, the reflex irritation of somatic and autonomic nerves to the spinal level caused by spinal dysfunction with areas of muscle stiffness and pain. Secondly, this mechanical disturbance affects neurological function of the chest wall by changing the tone airway responsiveness or airway directly through neurogenic inflammation, resulting in a predisposition to asthma induction. Another theory is that the correction of the dysfunction or vertebral subluxation by manipulation, with restoration of mechanical and nerve function, should improve airway function and assist in the resolution of asthma. ${ }^{(9)}$ Another addressed aspect would be the standardization of the parasympathetic flow through the Craniosacral therapy according to the protocol proposed by Upledger. ${ }^{(10)}$

Notable improvements ( $25 \%$ to $70 \%$ ) in patients peak expiratory flow rate (PEFR) have been reported following use of OMT. This positive effect has been attributed to several factors, including the decrease in patients' anxiety levels, the autonomic nervous system changes that relax the airways and smooth muscle tone, and especially the mechanical improvement of the chest wall. ${ }^{(9)}$

Finally, based on the rationale above, and the need to identify non-drug treatments feasible for the treatment of asthma, this study aimed to gather evidence tested osteopathic approach to treating the symptoms, respiratory dysfunction, medication use and quality of life of patients with chronic asthma.

\section{METHOD}

This is a literature review study of scientific articles examining the effects of osteopathy in the non-drug treatment of asthma. The literature review involved the electronic databases in health sciences Scielo, Lilacs and Medline, accessed via PubMed, Virtual Health Library and Google Scholar, and found manual queries references of articles, in order to prevent major studies were not identified and analyzed.

Electronic searches were conducted between October and November 2014 using as crossed descriptors, or alone in the fields "words", "subject descriptors", "title words", "title" and "summary", the following keywords combined with the Boolean operators AND and OR, namely: Osteopathic Medicine, osteopathic manipulation, osteopathy, Spinal Manipulation, Manual Therapy, Therapy Skull Sacral, Chiropractic, Chiropractic Manipulation, Asthma and their corresponding in Portuguese and Spanish. Initially they were collected all the articles that addressed the manual features used by osteopathic or chiropractic correlated with the asthma treatment published between the years 1998 and 2014.

For inclusion, the selected items should be clinical trials, randomized or not and case studies that addressed the technical manipulation of the spine, sacral skull therapy or any other osteopathic technique in patients of any age with asthma, reporting to clinical course, lung function, symptoms, medication use and quality of life. In addition, it was decided not to include a literature review of articles, abstracts published in conference proceedings, monographs, dissertations, comments and reviews, as it would be logistically impossible.

\section{RESULTS}

Using the proposed descriptors and through the manual search of references to other works, it was identified 35 references, of which 28 were excluded for not fit the previously defined inclusion criteria. An article published in 1998, was included by consensus meeting to contain information relevant to the subject. Thus, seven works were part of this review. Of which four are clinical trials,,$^{(8,9,10,11)}$ two case studies $^{(12-13)}$ and a pilot study. ${ }^{(5)}$ 


\section{DISCUSSION}

Interventions in controlling the symptoms of asthmatic patients using the Manipulative techniques have been approached by several researchers in an effort to find evidence to justify its application. However, there are still disagreements on valuation practices, comparative parameters, techniques and results.

In this sense, Balon et al., (9) in 1998 conducted a randomized double blind clinical trial consisting of 80 children and adolescents aged 7-16 years diagnosed with asthma in bronchodilator use and pain with spinal palpation. It was used as comparator parameter to the forced expiratory volume in one second after inhalation of $200 \mathrm{mg}$ of salbutamol, we applied a questionnaire of quality of life in pediatric asthma consists of 23 items ( 10 on symptom, 5 on activities and 8 on issues emotional). The patients were divided into 2 groups. The intervention group of 38 individuals and the placebo group containing 42 participants. The active treatment group received 20 to 36 sessions over 4 months. The treatment consisted of thoracic manipulation according to the level of dysfunction and mild soft tissue mobilization of the treated area, but there was no standardization of the technique used since some patients were seen by different chiropractors, all with over five years of clinical experience. The results did not achieve statistical significance, however, indicated that both groups showed improvement in expiratory flow, in subjective symptoms, beta-agonist use and quality of life.

Reinforcing these findings, another randomized blind clinical trial conducted by Bronfort et al., ${ }^{(5)}$ in 2001, studied a total of 34 patients aged 6 to 17 with mild to moderate asthma diagnosis. Initially the severity of symptoms was determined based on the presence of symptoms weekly, nightly, forced expiratory volume in one second and/or expiratory peak flow. All patients were clinically controlled by medication underwent prior evaluation of peak expiratory flow and spirometry was also validated questionnaire used to assess the quality of life and severity of asthma before and 12 weeks after treatment. The patients were divided into two groups. Group 1 with 22 patients, was treated through the manipulations of vertebral segments dysfunction (Trust). Once the Group 2, with 12 patients, false manipulations were made. At the end of intervention phase, the active manipulation group showed little or no change in pulmonary function tests and perception of improvement in daytime and nighttime symptoms. These findings corroborate the exposed by Balon, ${ }^{(9)}$ observed reduction of approximately $20 \%$ in the use of bronchodilator and improvement in quality of life between $10 \%$ and $28 \%$. Furthermore, other positive findings appear not evaluated by Balon ${ }^{(9)}$ such as a reduction in $39 \%$ of asthma severity classification and improvement of $50 \%$ to $75 \%$ overall. Suggesting that although they do not present significant changes in the pulmonary function, the children showed a substantial improvement in quality of life and asthma severity. However, the improvements observed cannot be associated with only specific effects of manipulative technique.

Bockenhauer et al., ${ }^{(8)}$ in 2002 held a non-controled study, with a sample containing 10 patients diagnosed with chronic asthma, women, aged between 35 and 59 years, smokers ${ }^{(4)}$ and nonsmokers, ${ }^{(6)}$ symptoms controlled and without modification of drug prescription during the study period. They used as comparative parameters before and after the intervention of osteopathic manipulations (OM), the measurement of chest excursion in two locations (upper and lower) measured peak expiratory peak flow (EPF) and the subjective perception of symptoms. The intervention lasted 10 to 15 minutes and consists of the application of osteopathic manipulative techniques (OMT) in sequence: release of the ligament strains of occipitocervical and cervicothoracic junction joints, T. Still technique for first elevated rib, direct manipulation for restriction in relegation rib in exhalation and diaphragmatic release. The same patients underwent after the first week, a placebo treatment, with techniques not recognized as OMT, the same assessment procedures being applied before and after the intervention, performed applied when the OMT. Regarding the results it was found that the excursion of the rib cage with labored breathing significantly increased following a single intervention, using OMT procedures. The subjective evaluation of symptoms improved somewhat after OMT procedures compared with the simulated procedures, but the difference was not statistically significant. The EPF rate also decreased after OMT and false procedures, although apparently after OMT procedures, the numbers were not statistically significant, improvement being assessed only from a qualitative point of view.

Although a smaller sample, with a higher age and with the use of different techniques when compared to studies of Balon $^{(9)}$ and Bronfort, ${ }^{(5)}$ the findings in relation to EPF, as well as the subjective perception the symptoms are similar.

In 2005, Guiney et al., ${ }^{(11)}$ published a randomized controlled clinical trial, which included a sample of 140 patients of both sexes, aged 5 to 17 years, diagnosed with asthma, controlled by treatment and monitored by EPF. The sample was divided into two groups. Group 1 ( $n=90)$, OMT and group $2(n=50)$, control group (false procedure). The OMT was based on the application of techniques to correct malfunctions in the ribs and chest region. The techniques were elected Rib raising (lifting ribs supine), muscle energy for ribs and myofascial release. PEF were measured before and after BMT and data analysis BMT group with t tests, had a statistically significant improvement from 7 liters per minute and 19 liters per minute; with an average improvement of 13 liters per minute. This improves not evident in the control group. The results suggest that the manipulative osteopathic treatment had a significant therapeutic effect between the population served. These findings differ from the results obtained in the three described above works, perhaps for having a larger sample. 
Another aspect that should be taken into consideration is that the techniques used in this study are different from those applied in the studies analyzed earlier, suggesting that this approach may be more efficient.

Mehl-madrona et al. ${ }^{(10)}$ conducted a randomized clinical trial, which sought to assess whether additional technical acupuncture and therapy sacral skull influence on pulmonary function and quality of life for people suffering from asthma, as well as in reducing anxiety, depression and medication. With 89 patients, aged between 20 and 80 years made up $73.5 \%$ of women, divided into five groups: acupuncture (12 sessions), craniosacral therapy (12 sessions), acupuncture and craniosacral ( 6 sessions each), control and waiting list. 68 completed the study. The variables evaluated were the lung function test Asthma Quality of Life (quality of life in asthma), medication use, depression and anxiety. In craniosacral therapy group the therapist accompanied the craniosacral rhythm with your hands and then held other soft reviews and manipulations with techniques according to the protocol proposed by Upleged Institute in Michigan. The parameter analysis was conducted in four stages: pre-treatment (two weeks before), post-treatment (up to 2 weeks), 3 and 6 months. The results showed that the pulmonary function tests were unchanged in all groups. However, improving the quality of life and reducing the use of drugs was higher in groups that received treatment when compared to control groups pointing to the importance of the inclusion of therapies to complement the treatments. There was no significant change in relation to depression and anxiety. These findings converge with the findings of other studies $^{(5,8-10)}$ however, it is important that the reduction of drug use and the maintenance of lung function can be considered as a positive aspect.

Green $^{(12)}$ published in 2000, a case study with a female patient, 43 years, diagnosed with chronic asthma, evaluation showed pain and stiffening of upper thoracic region, pain on active movement of this segment, restriction between low and high cervical thoracic, and joints costovertebral bilaterally between the second and fifth thoracic vertebra (T2-T5) and hypertonic muscles site. Spirometry was performed to evaluate EPF. The treatment was the low cervical spinal manipulation, high thoracic, costovertebral articulations, deactivation of trigger points, massage and relaxation techniques after isometric contraction, home use guidance cryotherapy, muscle stretching exercises to rhomboid, scalene and chest and movements cervical soft assets. After 12 months of treatment, the patient reported improvement of symptoms of asthma, presented a EPF modification 430l/min to 550L/min and there was also a reduction in the need of medication. The positive evolution of EPF, despite being an important functional improvement cannot be regarded as a significant result because of the study design and especially when compared to other randomized clinical trials. ${ }^{(5,8-10)}$ However, corroborates this regard with research Guiney ${ }^{(11)}$ and like all other cited studies point to the positive treatment response in relation to asthma symptoms and reducing the need for medications. . $^{(5,8-10)}$

The study of Gibbs(13) in 2005 presented three case reports of patients, one man and two women aged between 26 and 56 years, treated by conventional pharmacological method and were subjected to manipulation in the upper thoracic region (T2-T5), two times a week for a period of 6 weeks. The objective parameters were collected using a peak flow meter and the subjective data collected through a Visual Analogue Scale (VAS) used to classify the severity of symptoms ranging from 0 (very bad) to 10 (very healthy). The parameters were measured at three times (at the beginning, middle and end of treatment) and calculated the average of the EPF and VAS and compared the results of three collections. The results indicate similar levels of improvement in three patients regarding the evolution of EPF and analysis of VAS on the perception of asthma symptoms. Although the methodology does not seem the most suitable for making conclusions there are two aspects that must be confronted. The first is the improvement of EPF which is controversial when compared with most studies $^{(5,8-10)}$ and the second is the improvement of the subjective perception of asthma symptoms is present in all the research on the topic, regardless the methodology used. ${ }^{(5,10-13)}$

\section{CONCLUSION}

The findings compiled in this review suggest that osteopathic manipulative techniques can be used as non-medicated additional resource in the treatment of patients with asthma, since aspects such as quality of life, subjective perception of symptoms and reduce the use of drugs have positive growth in most of the studies cited. Research indicates few or no improvement in pulmonary function test. However, there is still no consensus on the best methodology for evaluation and treatment to be used, as well as the ideal combination of osteopathic manipulative techniques.

\section{AUTHORS CONTRIBUTION}

RVML, MAFSF: Design and research design, data retrieval, analysis and interpretation of data and critical revision of the manuscript regarding the important intellectual content; RVML, ACNS: Manuscript writing; ACNS: Final revision of the manuscript.

\section{COMPETING INTERESTS}

The authors declare no conflicts of interest.

\section{AUTHOR DETAILS}

${ }^{1}$ Osteopathy Specialist, Instituto Salvador de Ensino e Cultura, Salvador, (BA), Brazil. ${ }^{2}$ Osteopathy Specialist, Instituto Bahiano de Reabilitação (IBR), Salvador, (BA), Brazil. 


\section{REFERENCES}

1. World Health Organization. Global surveillance, prevention and control of chronic respiratory diseases: a comprehensive approach. Geneva: World Health Organization, 2007.

2. Gina - Guia de bolso para tratamento e prevenção da asma - Global Initiative for asthma 2014.

3. Santos PM, D'Oliveira Júnior A, Noblat LACB, Machado AS, Noblat ACB, Cruz AA. Preditores da adesão ao tratamento em pacientes com asma grave atendidos em um centro de referência na Bahia. J Bras Pneumol. 2008;34(12): 995-1002.

4. Rowane WA, Rowane MP. An osteopathic approach to asthma. J Am Osteopath Assoc. 1999 May;99(5):259-64.

5. Bronfort G, Evans RL, Kubic P, Filkin P. Chronic pediatric asthma and chiropractic spinal manipulation: a prospective clinical series and randomized clinical pilot study. J Manipulative Physiol Ther. 2001 JulAug;24(6):369-77.

6. Clinical Guideline Subcommittee on Low Back Pain; American Osteopathic Association. American Osteopathic Association guidelines for osteopathic manipulative treatment (OMT) for patients with low back pain. J Am Osteopath Assoc. 2010 Nov;110(11):653-66.
7. The American Association of Colleges of Osteopathic Medicine. Glossary of osteopathic terminology. Disponível em: www.aacom.org/resources/ bookstore/Documents/GOT2011ed.pdf.

8. Bockenhauer SE, Julliard KN, Lo KS, Huang E, Sheth AM. Quantifiable effects of osteopathic manipulative techniques on patients with chronic asthma. J Am Osteopath Assoc. 2002;102(7):371-75.

9. Balon J, Aker PD, Crowther ER, Danielson C, Cox PG, O'Shaughnessy $D$, et al. A comparison of active and simulated chiropractic manipulation as adjunctive treatment for childhood asthma. N Engl J Med. 1998 Oct 8;339(15):1013-20.

10. Mehl-Madrona L, Kligler B, Silverman S, Lynton H, Merrell W. The impact of acupuncture and craniosacral therapy interventions on clinical outcomes in adults with asthma. Explore (NY). 2007 Jan-Feb;3(1):28-36.

11. Guiney PA, Chou R, Vianna A, Lovenheim J. Effects of Osteopathic Manipulative Treatment on Pediatric Patients with Asthma: A Randomized Controlled Trial. J Am Osteopath Assoc. 2005;105:7-12.

12. Green A. Chronic asthma and chiropractic spinal manipulation: a case study. Br J Chiropr. 2000; 4(2-3):32-5.

13. Gibbs AL. Chiropractic co-management of medically treated asthma. Clin Chiropr. 2005;8:140-144. 